\title{
Anabases
}

ANABASES Traditions et réceptions de l'Antiquité

$18 \mid 2013$

Varia

\section{Hervé DUCHÊNE (éd.), Numa Denis Fustel de Coulanges, Leçons sur Sparte}

Stéphane Ratti

\section{OpenEdition}

Journals

Édition électronique

URL : http://journals.openedition.org/anabases/4396

DOI : $10.4000 /$ anabases.4396

ISSN : 2256-9421

\section{Éditeur}

E.R.A.S.M.E.

\section{Édition imprimée}

Date de publication : 1 octobre 2013

Pagination : 276-278

ISSN : 1774-4296

\section{Référence électronique}

Stéphane Ratti, "Hervé DUCHÊnE (éd.), Numa Denis Fustel de Coulanges, Leçons sur Sparte », Anabases [En ligne], 18 | 2013, mis en ligne le 01 janvier 2013, consulté le 22 septembre 2020. URL : http:// journals.openedition.org/anabases/4396 ; DOI : https://doi.org/10.4000/anabases.4396

Ce document a été généré automatiquement le 22 septembre 2020.

(c) Anabases 


\title{
Hervé DUCHÊNE (éd.), Numa Denis Fustel de Coulanges, Leçons sur Sparte
}

\author{
Stéphane Ratti
}

\section{RÉFÉRENCE}

Hervé DUCHÊNE (éd.), Numa Denis Fustel de Coulanges, Leçons sur Sparte, Paris, Éditions

EHESS, coll. « Audiographie », 2013, 85 p.

8 euros / ISBN 978-2-7132-2373-0.

1 Les éditions de l'EHESS proposent depuis 2011 une nouvelle collection lancée « sur une idée de Ph. Artières et J.-F. Bert» et qui porte un nom à la fois révélateur et énigmatique, du moins si l'on n'en connaît pas le principe : «Audiographie ». Il s'agit, en l'occurrence, de publier les manuscrits inédits ou les transcriptions méconnues d'un auteur devenu un classique et qui furent originellement livrés à leurs auditeurs sous la forme d'interventions publiques, de conférences de presse, de cours magistraux, d'entretiens radiophoniques ou télévisés. Bref, des textes initialement marqués par un effort de pédagogie ou "tournés vers la transmission ». Cinq volumes sont déjà parus autour de textes de Michel Foucault, Émile Durkheim, François Furet, Serge Moscovici et Quentin Skinner. Chaque volume est présenté et annoté par un spécialiste de l'auteur. La collection a choisi d'adopter un petit format et un nombre limité de pages, selon une mode garantie d'un certain succès. Les volumes - papier, typographie, mise en page - sont matériellement très soignés et fort agréables à lire.

2 Le sixième volume de la collection est présenté par Hervé Duchêne (H. D.), Professeur d'Histoire grecque à l'université de Bourgogne, et nous fait connaître un texte inédit de Fustel de Coulanges (1830-1889). Il s'agit en l'occurrence du cours professé par ce dernier aux normaliens à la rue d'Ulm en 1876 et qui portait, cette année-là, sur la cité grecque, Athènes et ses institutions. De ce corpus, H. D. publie ici les leçons consacrées spécifiquement à Sparte. Après un passage à Strasbourg, Fustel est désormais Maître de Conférences à l'École normale. L'importance d'un historien que Julien Benda présentait 
comme l'un des promoteurs, après Voltaire ou Renan, de «la charte de l'histoire désintéressée » (La trahison des clercs, éd. 2011, p. 189), n'est plus à démontrer (sur l'homme et ses paradoxes on lira l'excellent livre de F. Hartog, Le XIX ${ }^{e}$ siècle et l'histoire. Le cas Fustel de Coulanges, 1988, rééd. 2001). Son cours d'histoire grecque a été conservé dans les archives grâce aux notes prises par deux élèves de la promotion 1876 : Salomon Reinach (1858-1932) et Émile Groussard (1856-1904). On connaît bien le premier, futur conservateur du Musée de Saint-Germain-en-Laye et directeur pendant près d'un demisiècle de la Revue archéologique, moins bien le second qui deviendra professeur au Lycée Janson de Sailly.

3 Avant d'en venir au contenu de ce cours, un mot sur l'idée fort astucieuse de l'éditeur qui a choisi de publier en parallèle (en regard en fait) les notes prises par les deux élèves. En réalité ce sont les notes de Groussard qui fournissent l'essentiel du texte publié car, en bon élève, il a non seulement, selon toute apparence, mis au net mais réécrit et mis en forme ses notes a posteriori, mais encore il accorde un soin constant au style de son propre texte et il cherche même, comme le remarque H. D., à reproduire l'éloquence du Maître. Reinach, de son côté, se montre lapidaire dans la prise de notes : il privilégie les grandes lignes, non sans faire preuve d'un esprit de synthèse déjà acéré, condense sous forme de formules (personnelles souvent, empruntées à Fustel parfois) l'enseignement reçu, relève à certain moment telle incohérence ou telle difficulté avec une assurance qui laisse deviner l'esprit fort. Il y a quelque chose d'émouvant à être ainsi introduit dans l'intimité non seulement d'une École mais encore dans celle de la conscience d'un futur grand savant en formation. L'intérêt de ce type de publication, réel, est finalement à plusieurs facettes : il concerne tout à la fois le cours d'un Maître, la réaction de ses élèves, eux-mêmes appelés à exercer le métier, et le fonctionnement d'une Institution puisque les élèves sont invités à prendre la parole au cours du séminaire. Ces cours mis en forme circulaient entre élèves et entre promotions ; ces cahiers servaient, dans leur propre enseignement, aux anciens élèves, une fois le moment venu pour eux de prendre à leur tour une classe.

4 Précisément que contient le cours de Fustel ? Il débutait par un aperçu méthodologique sur les sources, relevait l'importance des archives dans les cités, soulignait ensuite les « creux » dans notre connaissance de ce monde lointain: "Thucydide n'a pas un mot sur les arts, ni sur les artistes. Rien sur l'industrie, rien sur le commerce. C'est à peine si de temps en temps les historiens nous indiquent le nom des différentes classes de la société. Il faut chercher ces renseignements ailleurs ». Un autre cours portait sur les indo-européens et leur langue. Fustel insistait encore sur les origines lointaines (avant Agamemnon) de la civilisation grecque. Cinq leçons au total, ici reproduites, portent sur Sparte: organisation sociale de la cité, description de la société spartiate, les réformes de Lycurgue. Reinach note dans une de ses dernières remarques: "Le gouvernement de Sparte n'était donc pas une monarchie : aei atyranneutos, "elle ne connut jamais la tyrannie », dit Thucydide $(I, 18) »$.

5 Comme le souligne à juste titre H. D., le cours de Fustel sur Sparte « appartient tout à la fois au passé, au présent et à l'avenir des travaux fustéliens ». La Cité antique est parue douze ans plus tôt, en 1864, et Fustel y prend une ligne directrice du cours, l'illustration du mécanisme par lequel «l'autorité politique est enlevée aux rois ». Il songe d'autre part déjà, à cette époque, à ses futures publications sur le droit de propriété à Sparte.

H. D., grand spécialiste de l'histoire personnelle de Salomon Reinach, sait admirablement présenter les hommes et les institutions qui les ont formés et qu'ils sont 
appelés, plus tard dans leur carrière, à diriger. Son récit, clair, vivant, informé, dans une introduction de 27 pages, tire le meilleur des archives. Avec une érudition parfaitement maîtrisée, notre collègue sait faire revivre ces élèves, leur Maître et leur École. Les spécialistes de la question des transmissions des savoirs mais aussi le lecteur curieux tireront le plus grand profit en même temps qu'un vrai plaisir à la lecture de ce document toujours juste et parfois touchant.

\section{AUTEURS}

\section{STÉPHANE RATTI}

Université de Franche-Comté/EHESS

stephane.ratti@u-bourgogne.fr 